\title{
Identification of halal risk in risoles production using house of risk method
}

\author{
Dini Wahyuni ${ }^{1 *}$, Nazaruddin ${ }^{1}$, Talitha Almira Muharrami ${ }^{1}$, and Irwan Budiman ${ }^{2}$ \\ ${ }^{1}$ Department of Industrial Engineering, Faculty of Engineering, Universitas Sumatera Utara, \\ Indonesia, 20155 \\ ${ }^{2}$ Department of Industrial Engineering, Faculty of Technology and Computer Sciences, Universitas \\ Prima Indonesia, Indonesia, 20111
}

\begin{abstract}
This research was conducted at Food Micro, Small and Medium Enterprises (MSMEs) in Medan City. In this study, observations were made on all activities, so that the process stages and risks that affect halal in each stage of the process are known. Furthermore, the risk factors are identified, and the House of Risk (HOR) method is used to find the dominant cause through the calculation of the Aggregate Risk Potential (ARP). The results showed that there were 9 processes, 31 risk events, and 26 risk agents. Ideally, no risk agent can affect the halal of the product. However, treatment priorities can be set to address the risk agent that has the greatest impact, which is based on the highest ARP value. In this study, the focus of handling is five risk agents, namely raw materials that are not entirely Halal certified, cleaning of machinery and equipment is not routinely carried out before starting production, raw materials received from suppliers are not following demand, working environmental conditions make it difficult for workers to concentrate, and lack of halal management and information system.
\end{abstract}

\section{Introduction}

Every Moslem must comply with Sharia principles and every product or service must not contain non-halal content. Halal food must be free from any haram components. Halal has become a global symbol for quality assurance [1]. The halal food business has increased by $17 \%$ of the world's food trade. Nowadays, countries with Moslem minorities are even becoming global halal food producers [2].

In halal food production activities, the main principle is that the product is not even contaminated with non-halal ones [3]. The halal status of the product can be lost because it is contaminated with the haram during transportation and storage [4]. Halal involves all supply chain networks, from source to end consumer, from farm to fork [5].

The existence of halal assurance (halal-certified product) is an added value in today's competitive food industry. Halal assurance is not only required for the final product but also at every stage of the supply chain. With the existence of halal assurance, processes related to halal criteria can be analyzed [6]. Many factors influence the Halal Food Supply Chain.

* Corresponding author: diniwahyuni2015@gmail.com 
Consumer trust is the main thing, in addition to maintaining the integrity of halal products throughout the supply chain. Halal food must be avoided from dubious things (its status or ingredients) because Moslem consumers are sensitive to halal issues, as well as lack of control over regulations [7]. Some problems in handling halal products occur in air cargo warehouses [8]. In the supply chain, the risks that occur can simultaneously affect food safety and its halal status [9].

At present, halal food products are no longer seen as a mere religious necessity in the Moslem community. In the non-Moslem community, there is also a perception that halal food is more hygienic, clean, and delicious. This makes halal food products known and no longer a niche market but has approached 16\% [10], even 17\% [11] of the world food trade.

Halal certification requirements require a halal policy, a halal management team, training and education, materials, products, production facilities, written procedures for critical activities, traceability, handling of products that do not meet the criteria, internal audits, and management reviews. Halal raw materials that have been processed in clean and halal facilities are expected to become halal products. However, halal food can also turn into haram due to several factors, such as the result of stealing, the result of haram work, or mixed with haram food, and not being slaughtered in the name of Allah [12].

In this study, analysis and evaluation of risks that could potentially lead to not halal processed foods were carried out using the HOR (House of Risk) approach. The concept of HOR will help to design strategies so that it can identify risks and prioritize risk events that must be handled first, as well as design treatment strategies to reduce or eliminate identified risk agents.

\section{Method}

The objects observed in this study were all stages of the process in MSMEs that produce rissoles, starting from the procurement of raw materials to the products being distributed to consumers. MSME which is the object of research produce halal risoles but does not have a Halal certificate. Data collection is done by:

- Each stage of the process is observed to find out what risks have the potential to affect the halal status of the product.

- Head of the production department interviewed regarding the observed risk events and risk agents.

- Questionnaires were given to halal auditors from LPPOM MUI SUMUT to get input regarding MSME problems during halal certification

Data processing in this study was carried out using the House of Risk method to determine which sources of risk are prioritized for preventive action. The data processing stages are as follows:

- Risk events were identified in each business process that occur. This is done by mapping all stages of the process and then identifying what is missing or wrong at each stage of the process

- Possible impact of several risk events (severity) assessed using a scale of 1 to 10 , whereas a scale of 10 indicates extreme impacts.

- Sources of risk were identified and assessed the likelihood of occurrence of each risk source (risk agent). The likelihood rating was assessed using a scale of 1 to 10 , whereas a scale of 10 indicates a very frequent condition.

- Relationship matrix was developed between each risk source and each risk event, Rij $(0,1,3,9)$ where 0 indicates no correlation, and 1,3 , and 9 show low, medium, and high correlations, respectively. 
- Aggregate Risk Potential of agent $\mathrm{j}=$ ARPj calculated, which is determined as the result of the likelihood of events from risk source $j$ and the collection of the causal effects of each risk event caused by risk source $\mathrm{j}$ as in the equation:

$$
\operatorname{ARP}_{\mathrm{j}}=\mathrm{O}_{\mathrm{j}} \sum \mathrm{S}_{\mathrm{i}} \mathrm{R}_{\mathrm{j}}
$$

Where Oj is the likelihood of the risk source event $\mathrm{j}$, Si is the severity of the effect if risk $\mathrm{i}$ occurs, and $\mathrm{Rj}$ is the correlation between risk source $\mathrm{j}$ and risk event $\mathrm{i}$ (indicating how likely it is that risk source $\mathrm{j}$ goes to risk event $\mathrm{i}$ ).

- Ranking risk sources based on the pool of potential risks in descending order (from large to lowest).

\section{Results and discussion}

Table 1. Risk Event in rissoles production

\begin{tabular}{|c|c|c|}
\hline Process & Risk Event & Code \\
\hline $\begin{array}{l}\text { Procurement of raw } \\
\text { materials }\end{array}$ & $\begin{array}{l}\text { The raw materials have no clear halal status } \\
\text { No halal consideration in administrative procurement } \\
\text { Suppliers delay in the delivery of raw materials } \\
\text { Incompatibility of raw materials received } \\
\text { Raw materials received are contaminated with unclean } \\
\text { Raw materials received have the potential to expire } \\
\text { Procurement of raw materials that are not halal-certified }\end{array}$ & $\begin{array}{l}E_{1} \\
E_{2} \\
E_{3} \\
E_{4} \\
E_{5} \\
E_{6} \\
E_{7}\end{array}$ \\
\hline Rissoles skin making & $\begin{array}{c}\text { The eggs used still dirty } \\
\text { The use of contaminated flour } \\
\text { Use of unsanitary equipment and machinery } \\
\text { During the fermentation process, the dough is contaminated with } \\
\text { foreign objects and unclean } \\
\text { The finished skin is not stored in a clean container } \\
\text { Workers pay less attention to work instructions }\end{array}$ & $\begin{array}{l}E_{8} \\
E_{9} \\
E_{10} \\
E_{11} \\
E_{12} \\
E_{13}\end{array}$ \\
\hline $\begin{array}{l}\text { Making Rissoles } \\
\text { filling }\end{array}$ & $\begin{array}{l}\text { The vegetables used contaminated by feces and parasite } \\
\text { Use of unsanitary equipment and machinery } \\
\text { The use of contaminated flour } \\
\text { Felling dirt during the stirring process } \\
\text { The finished filling is not stored in a clean container } \\
\text { Workers pay less attention to work instructions }\end{array}$ & $\begin{array}{l}E_{14} \\
E_{15} \\
E_{16} \\
E_{17} \\
E_{18} \\
E_{19}\end{array}$ \\
\hline $\begin{array}{l}\text { Rissoles filling and } \\
\text { wrapping }\end{array}$ & $\begin{array}{c}\text { The used panir is contaminated by dirt } \\
\text { The eggs used still dirty } \\
\text { Use of unsanitary equipment } \\
\text { Workers pay less attention to work instructions }\end{array}$ & $\begin{array}{l}E_{20} \\
E_{21} \\
E_{22} \\
E_{23}\end{array}$ \\
\hline Rissoles fryer & The fallen Rissoles are put back into the frying pan & $\mathrm{E}_{24}$ \\
\hline Product storage & $\begin{array}{c}\text { The packaging is unable to prevent contamination } \\
\text { Contaminated finished product } \\
\text { The freezer box used is damaged so it is not effective to store } \\
\text { frozen Rissoles }\end{array}$ & $\begin{array}{l}E_{25} \\
E_{26} \\
E_{27}\end{array}$ \\
\hline $\begin{array}{l}\text { Delivery of products } \\
\text { to customers }\end{array}$ & $\begin{array}{l}\text { The shipping process is potentially contaminated with unclean } \\
\text { The packaging material is damaged in the shipping process }\end{array}$ & $\begin{array}{l}E_{28} \\
E_{29}\end{array}$ \\
\hline $\begin{array}{l}\text { Product returns from } \\
\text { customers }\end{array}$ & $\begin{array}{l}\text { Food has reached its expiration date } \\
\text { Contaminated with at the time of product return }\end{array}$ & $\begin{array}{l}E_{30} \\
E_{31}\end{array}$ \\
\hline
\end{tabular}

Source: Interview 
A risk event is an event that can disrupt the activities of the company. The risk event is obtained from the results of interviews and observations which are then coded using the letter $\mathrm{E}$ which aims to facilitate further reading. The risk event at the company can be seen in Table 1.

Risk agents are things that can cause a risk event to occur so that it can interfere with the activities of the company. The risk agent is obtained from the results of interviews and observations which are then coded using the letter A which aims to facilitate further reading. The company's risk agent can be seen in Table 2 .

Table 2. Risk agents in rissoles production activities

\begin{tabular}{|c|c|}
\hline Risk Agent & Code \\
\hline Ignorance of the halal status of raw materials from suppliers & $\mathrm{A}_{1}$ \\
\hline Lack of halal management and information system & $\mathrm{A}_{2}$ \\
\hline Limited means of transportation & $\mathrm{A}_{3}$ \\
\hline Ignorance of the recipient of the raw material from the supplier & $\mathrm{A}_{4}$ \\
\hline Inaccuracy when checking raw materials received & $\mathrm{A}_{5}$ \\
\hline Storage of unsanitary and sterile materials & $\mathrm{A}_{6}$ \\
\hline Raw materials that are not entirely Halal certified & $\mathrm{A}_{7}$ \\
\hline Eggs are not washed thoroughly before use & $\mathrm{A}_{8}$ \\
\hline The flour is not covered and left open & $\mathrm{A}_{9}$ \\
\hline $\begin{array}{l}\text { Cleaning of machinery and equipment is not routinely carried out before starting } \\
\text { production }\end{array}$ & $\mathrm{A}_{10}$ \\
\hline Error in the fermentation process of the dough which causes contamination & $\mathrm{A}_{11}$ \\
\hline $\begin{array}{l}\text { Limitations of the available containers when making larger quantities of Rissoles } \\
\text { shells }\end{array}$ & $\mathrm{A}_{12}$ \\
\hline Working environmental conditions make it difficult for workers to concentrate & $\mathrm{A}_{13}$ \\
\hline There is still dirt on the vegetables that have been washed & $\mathrm{A}_{14}$ \\
\hline Error in the stirring process which causes contamination & $\mathrm{A}_{15}$ \\
\hline $\begin{array}{l}\text { Limitations of the available containers when making larger amounts of Rissoles } \\
\text { filling }\end{array}$ & $\mathrm{A}_{16}$ \\
\hline Uncovered panir flour and left open & $\mathrm{A}_{17}$ \\
\hline $\begin{array}{l}\text { The workers' ignorance that the fallen Rissoles could affect the halal of the } \\
\text { Rissoles }\end{array}$ & $\mathrm{A}_{18}$ \\
\hline The packaging still uses materials that are prone to contamination & $\mathrm{A}_{19}$ \\
\hline Less thorough when checking the final product & $\mathrm{A}_{20}$ \\
\hline Lack of maintenance on the freezer box so it becomes damaged quickly & $\mathrm{A}_{21}$ \\
\hline $\begin{array}{l}\text { The means of transportation have been used for goods whose halal status is not } \\
\text { clear }\end{array}$ & $\mathrm{A}_{22}$ \\
\hline Lack of caution in the process of sending finished products & $\mathrm{A}_{23}$ \\
\hline Raw materials received from suppliers are not following demand & $\mathrm{A}_{24}$ \\
\hline Product storage that is not separate from other products & $\mathrm{A}_{25}$ \\
\hline Transportation disruption & $\mathrm{A}_{26}$ \\
\hline
\end{tabular}

Source: Interview

Risk evaluation is carried out using the Pareto concept. $20 \%$ risk agent and the percentage of its effect on the Aggregate Risk Potential (ARP) value is a priority for further treatment. 15-highest-value of ARP can be seen in Figure 1. 


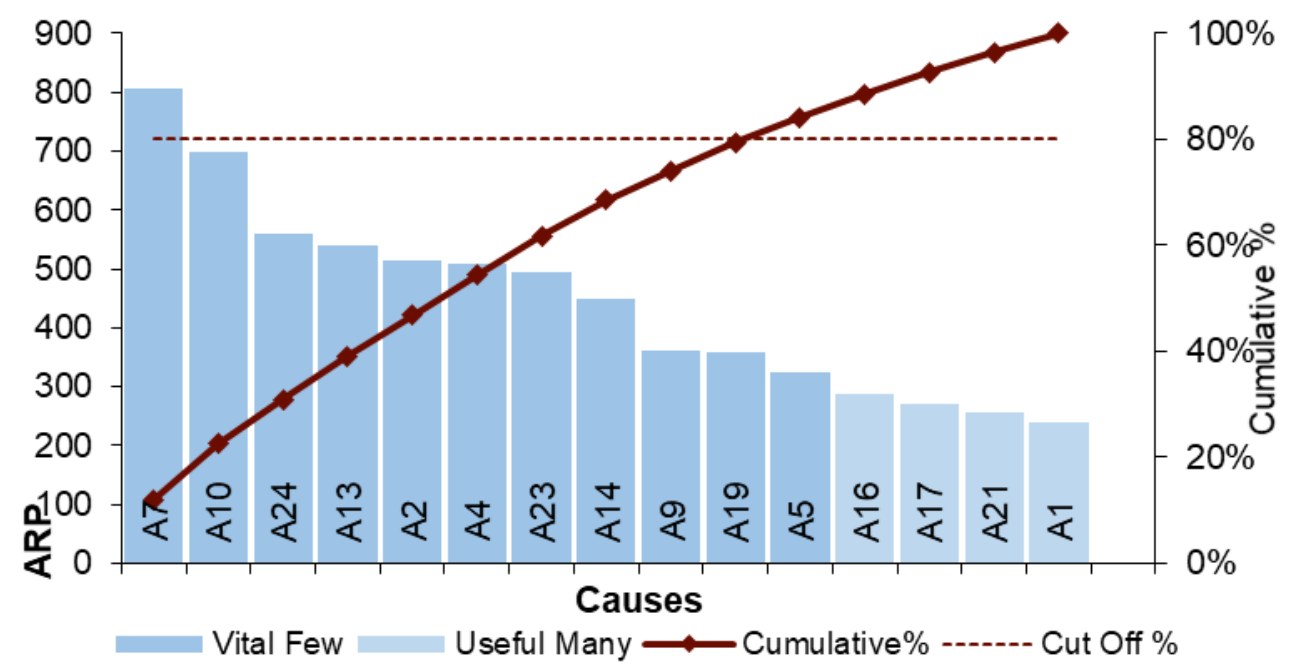

Fig. 1. Pareto ARP risk agent diagram

Five priority risk agents are selected as shown in Table 3.

Table 3. Risk Agent Priority

\begin{tabular}{|c|c|c|}
\hline Code & Risk Agent & ARP \\
\hline $\mathrm{A}_{7}$ & Raw materials that are not entirely Halal certified & 805 \\
\hline $\mathrm{A}_{10}$ & $\begin{array}{c}\text { Cleaning of machinery and equipment is not routinely carried out before } \\
\text { starting production }\end{array}$ & 699 \\
\hline $\mathrm{A}_{24}$ & Raw materials received from suppliers are not following demand & 560 \\
\hline $\mathrm{A}_{13}$ & $\begin{array}{c}\text { Working environmental conditions make it difficult for workers to } \\
\text { concentrate }\end{array}$ & 540 \\
\hline $\mathrm{A}_{2}$ & Lack of halal management and information system & 515 \\
\hline
\end{tabular}

Source: Data Processing

If the risk agent is allowed, it will result in the following things, namely:

- Procurement of raw materials with unclear halal status because they are not registered with LPPOM MUI, can cause the resulting product to doubt its halal status.

- The use of unclean equipment and machinery, which may be contaminated with unclean material (najis), can cause non-halal products.

- The discrepancy between the raw material received and the one ordered. Different materials can cause different product quality, besides affecting its halal status.

- Workers do not concentrate because of the hot environment, as result workers do not pay attention to work instructions at every stage of the process, where errors in work can affect halal of the products produced.

- Procurement and handling of raw materials are not supported by an administrative system that considers halal so that the halal product can be doubted.

This is in line with the results of research conducted by Supian (2018) which states that the uncertainty of the halal status of materials, material handling, equipment handling, and worker activities can affect the product's halal status [13].

In this study, a questionnaire was also given to several Halal auditors from the LPPOM MUI Sumatra Utara. The questionnaire nets some problems that auditors often encounter when conducting field audits. 
The five highest risk agents obtained in this study are in line with the input obtained from the Halal auditors, namely regarding the absence of complete procedures for procurement and handling of halal raw materials, problems in the transportation of materials and products, conditions of workspace and work facilities, and cleanliness of work environment. Another problem is poor administrative management, such as incomplete production records, material purchase documents, product delivery documents, as well as workers' lack of understanding and awareness of the importance of consistent Halal production activities.

The priority problems obtained from this research need to be immediately designed a mitigation action plan so that the resulting product is more ready for halal certification.

\section{Conclusion}

The conclusions that can be drawn from this study are as follows.

- Identification of the risk of halal in the 9 stages of the rissoles production process resulted in 31 risk events and 26 risk agents.

- Ideally, no risk agent can affect the halal of the product. However, treatment priorities can be set to address the risk agent that has the greatest impact, which is based on the highest ARP value. In this study, the focus of handling is five risk agents, namely raw materials that are not entirely Halal certified, cleaning of machinery and equipment is not routinely carried out before starting production, raw materials received from suppliers are not following demand, working environmental conditions make it difficult for workers to concentrate, and lack of halal management and information system.

This research is supported by the Universitas Sumatera Utara through TALENTA Research with contract number 4142 / UN5.1.R / PPM / 2020 dated April 27, 2020. We would also like to thank colleagues who provide views and expertise related to the research carried out.

\section{References}

1. M.S. Ab Talib, L. Rubin, VK Zhengyi, J. Emerging Economies and Islamic Research, 1, 2 (2013)

2. State of the Global Islamic Economy Report 2020/21, DinarStandard, (2021)

3. R. Syam, R.Z. Rasi, N. Abdamia, S. Mohamed, TKM T. Bibi, Halal Logistic Implementation in Malaysia: A Practical View, in Proceedings of the International Research and Innovation Summit, IRIS2017, IOP conf. Series: Materials Science and Engineering, 226, 012040 (2017)

4. S. Zailani, M. Iranmanesh, A.A. Azis, K. Kanapathy, J. Islamic Marketing, 8, 1 (2017)

5. M.S. Ab Talib, M.R.M. Johan, Int. Business and Management, 5, 2 (2012)

6. T.N. Ma'rifat, S. Purwanto, S. Windarwati, Agroindustr. Tech. J., 1. 1 (2017)

7. M. Tieman, J. Islamic Marketing, 8, 3 (2017)

8. N.A. Abdul Rahman, M.F. Mohammad, S. Abdul Rahim, H.M. Noh, J. Islamic Marketing, 9, 3 (2018)

9. H.C. Wahyuni, I.Vanany, U. Ciptomulyono, J.D.T. Purnomo, Supply Chain Forum: An International Journal, 21, 4 (2020) 
10. M.H. Zulfakar, M.M. Anuar, M.S. Ab Talib, Conceptual Framework on Halal Food Supply Chain: Integrity Enhancement, Social Process and Behavioral Sciences, 121 (2014)

11. A.A. Rahman, H.B. Singhry, M.H. Hanafiah, M. Abdull, J. Food Control, 73, B (2017)

12. M. Maghfiroh, J. Economia, 11, 2 (2015)

13. K. Supian, Preparation and Processing of Religious and Cultural Foods, p. 309-321 (2018) 